BEST PRACTICE

\title{
Management of paediatric asthma
}

\section{J Grigg}

Postgrad Med J 2004;80:535-540. doi: 10.1136/pgmj.2003.014936

Paediatric asthma best practice not only includes prescribing the correct therapeutic mix based on consensus guidelines, but also reducing therapy once control has been achieved. Clinicians should also be aware that asthma in young children is a heterogeneous entity, and a beneficial response to bronchodilators and/or inhaled steroids is not inevitable. In general, preschool children and infants should not be prescribed inhaled corticosteroids above $200 \mu \mathrm{g}$ beclometasone dipropionate equivalent twice a day, or regular oral steroids, or long acting $\beta_{2}$-adrenoceptor agonists. New therapies such as anti-lgE antibodies are on the horizon, but these are unlikely to replace the established drug combinations. More likely is that the delivery of established drugs will become more convenient (for example, once a day inhaled corticosteroids, or season dependent prophylactic therapy).

\section{Correspondence to: Dr Jonathan Grigg, Leicester Children's Asthma Centre, University of Leicester, Leicester LE2 7LX, UK; ig33@le.ac.uk}

Submitted

12 September 2003

Accepted 18 March 2004
$\mathrm{T}$ he incidence and prevalence of asthma in children has increased over the last three decades. ${ }^{1} \mathrm{New}$ cases of paediatric asthma are currently running at 70 per 100000 for the preschool age group, and 50 per 100000 for older children. ${ }^{1}$ There are many sources of information on how to treat asthmatic children, but the British Guideline on the Management of Asthma, published in 2003 by the British Thoracic Society is particularly useful. ${ }^{2}$ This guideline was developed using the rigorous methodology developed by the Scottish Intercollegiate Guidelines Network, and draws heavily on the conclusions of systematic reviews. The present review uses the British Thoracic Society guideline where appropriate, but also discusses the uncertainties in the published data, and includes personal practice points.

\section{ASTHMA PHENOTYPES}

Epidemiological data strongly suggest that there are different phenotypes of paediatric asthma composed of distinct clusters of risk factors, symptom patterns, and outcomes; and that the phenotype mix changes with age. Drawing on data from a large birth cohort study, ${ }^{3}$ Martinez has identified at least two asthma phenotypes in children under 6 years of age. ${ }^{4}$ First, "transient wheezing of infancy" - characterised by brief episodes of wheeze triggered by viral colds, starting in the first months of life and, in the majority, resolving by 6 years of age (alternative labels are "wheezy bronchitis" or "preschoolviral wheeze"). The second phenotype, is "atopic asthma"; this is an entity strongly associated with IgE mediated immune responses to aeroallergen, and one that constitutes the majority of school age asthmatics. ${ }^{4}$ Other studies have lent support to Martinez's view that transient wheeze and atopic asthma are distinct phenotypes. For example, in the 1960s, researchers in Melbourne, Australia, recruited children with (i) mild and severe "wheezy bronchitis" ( similar to "transient infant wheeze"), (ii) mild asthma (wheeze with and without colds), and (iii) severe asthma. Longitudinal follow up showed that children with wheezy bronchitis were asymptomatic as adults. In contrast, children with severe asthma (wheeze with and without colds starting at 3 years of age and continuing to at least 10 years) had a significantly increased risk of wheeze continuing into adult life, ${ }^{5}$ especially if there were atopic features such as hay fever, or a positive skin test to aeroallergen. ${ }^{6}$ Taken together, these data suggest that there is a marked heterogeneity of asthma phenotypes in preschool children. However it is important to note that the minority of wheezy preschool children will continue wheezing into school age. This group forms the majority (up to $80 \%$ ) of "atopic" school age asthmatics. ${ }^{7}$ There is a third possible phenotype of preschool asthma: "post-respiratory syncytial virus (RSV) wheeze". This describes infants between 3 and 18 months of age who develop episodic or persistent wheeze after RSV bronchiolitis; ; a distinct clinical syndrome characterised by acute tachypnoea, and wet cough and widespread crackles. ${ }^{8}$ Clinical RSV bronchiolitis undoubtedly increases the risk of subsequent wheeze. ${ }^{9}$ However this does not necessarily mean that RSV causes preschool wheeze since there may be common risk factors such as reduced lung function ${ }^{10}$ that predispose both to symptomatic RSV bronchiolitis (and an increased risk of hospital admission) and continued episodes of wheeze after RSV.

Since there is no accurate way of predicting whether wheeze in a preschool child will persist or resolve, discussion on outcome with parents must be statistical. A wheezy infant $<2$ years has a $60 \%-70 \%$ chance of stopping wheezing in early childhood and never developing atopic asthma. For a child from 2-6 years, and the wheeze is almost exclusively viral triggered, it is still unlikely that the child will wheeze into school age. If a child is around 6 years and is still wheezing, there is an increased chance of atopic

\footnotetext{
Abbreviations: BDP, beclometasone dipropionate; $\mathrm{FEV}_{1}$, forced expiratory volume in one second; LABA, long acting $\beta_{2}$-adrenoceptor agonist; $\mathrm{pMDI}$, pressurised metered dose inhaler; PEF, peak expiratory flow; RSV, respiratory syncytial virus
} 
asthma, but even then in later childhood a substantial minority will become asymptomatic. ${ }^{11}$

\section{PATHOGENESIS}

Bronchial biopsy specimens in adults show that the inflammatory substrate of atopic asthma is increased activation of "Th2" lymphocytes. ${ }^{12}$ These cells release cytokines that promote the terminal differentiation of committed eosinophil precursors, activate mature eosinophils to release histotoxic mediators, and enhance the recruitment of circulating eosinophils into the lung. ${ }^{13}$ A hallmark of adult atopic asthma is therefore increased numbers of eosinophils in the airway and bronchial mucosa. ${ }^{14}$ Increased numbers of eosinophils have also been found in the lower airways of school age children with asthma, ${ }^{15}$ and it is reasonable to assume that the inflammatory substrate (and therefore phenotype) of asthma in the majority of adults, school age children, and teenagers is similar. In contrast, the inflammatory substrate of transient wheeze in the majority of preschool viral wheeze is probably not the same as atopic asthma. For example, persistent airway eosinophilia is not present in the airways of preschool children with episodic wheezing during winter colds. ${ }^{16}$

\section{DIAGNOSIS}

\section{Clinical}

When taking the history from the parents and child, the clinician should ask details of past and current symptoms, symptom pattern, precipitating and aggravating factors, and the impact of symptoms on the child and family (fig 1). In older children, it is also useful to ask what they want treatment to achieve. A history of dry cough (especially at night), wheeze, shortness of breath, and chest tightness made worse by viral colds, passive smoke, exercise, changes in weather, crying, and laughing are hallmarks of atopic

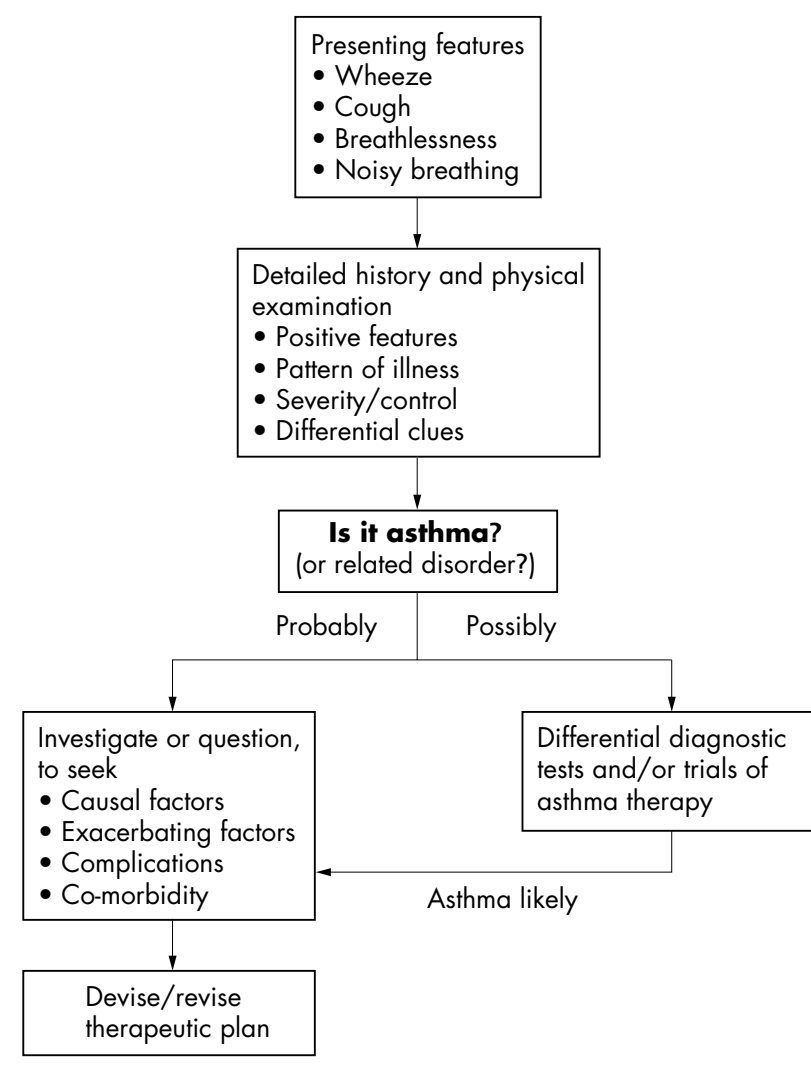

Figure 1 Diagnosis of asthma in children. asthma in school age children. A high level of suspicion of asthma is necessary, since not all parents can identify wheeze in their child. On the other hand, a diagnosis of asthma should initially be regarded as provisional. Persistent wet cough, failure to thrive, cyanosis, clubbing, dysphasia, abnormal voice, inspiratory stridor, and failure to respond to asthma therapy are warning signs that there may be an alternative diagnosis such as cystic fibrosis, foreign body aspiration, or immunodeficiency.

\section{Objective evidence}

Before starting potentially long term therapy it is important to try and obtain objective evidence of reversible bronchoconstriction. Most children can accomplish a forced expiratory manoeuvre by 7 years of age, and spirometry will detect those who have significant bronchoconstriction, at least on the day of consultation. "Baseline" bronchoconstriction is defined as a ratio of forced expiratory volume in one second $\left(\mathrm{FEV}_{1}\right)$ to forced vital capacity of $<75 \%$, or a "concave" expiratory flow/volume curve. If this pattern is present, a short term $\beta_{2}$-agonist should be given and spirometry repeated 15 minutes later (fig 2 ). A $>9 \%$ improvement of the $\mathrm{FEV}_{1}$ (\% predicted) after bronchodilator is strong evidence for asthma. ${ }^{17}$ Occasionally bronchodilator responsiveness can be found in children whose baseline lung function appears to be in the "normal" range. These children, in retrospect, have significant restriction superimposed on supranormal lung function. Many of the symptoms of asthma in school age children are a result of bronchial hyperreactivity. Significant bronchoconstriction can therefore be induced by inhalation of metacholine or hypertonic saline at a lower threshold in asthmatics-even during asymptomatic periods. However pharmacologically induced bronchoconstriction is rarely used in routine clinical practice. In contrast, a drop in peak expiratory flow (PEF) after treadmill exercise is helpful if exercise induced symptoms are reported, and no other objective evidence for asthma can be found. PEF variability (morning, evening, and after bronchodilator levels compared to "personal best") using a mini-flow meter is not accurate enough for diagnosis, but sometimes has a role in assessing response to therapy. In preschool children, wheeze on auscultation is often the only objective sign of asthma. ${ }^{2}$ In this age group, a short trial of inhaled $\beta_{2}$-agonist and/or a short course of oral corticosteroid may be the only alternative diagnostic option. ${ }^{7}$ It is important to note that many nonasthmatic conditions, such as non-atopic cough or bronchitis, are self limiting, and may therefore appear to improve during a trial of asthma therapy.

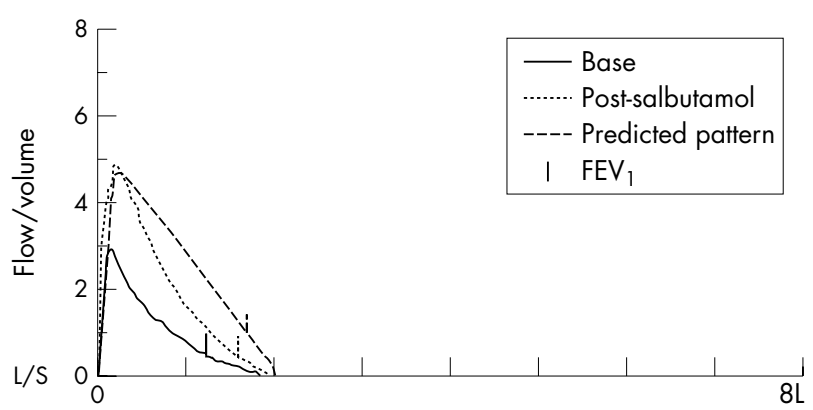

Figure 2 An expiratory flow/volume loop showing bronchial obstruction in a 14 year old boy. The $\mathrm{FEV}_{1}$ is $70 \%$ of predicted from normal values. There is a "concave" appearance of the loop strongly suggestive of small airways obstruction; 15 minutes post-salbutamol, the loop moves towards the normal predicted pattern and the $\mathrm{FEV}_{1}$ increases by $31 \%$. 


\section{MANAGEMENT \\ Goals}

The aim of treatment is to eliminate cough, wheeze, difficulty breathing, and night-time waking with wheeze or cough, and re-establish normal activity levels with no acute deteriorations that need medical help, no school absences, and normal level of lung function. ${ }^{7}$ The less obvious markers of asthma should also be addressed. These include periods of fatigue after exercise (typically the child will look pale and has to sit after play at levels below that of its peers), activity avoidance, and general complaints of "not felling well".

\section{Avoidance of triggers}

Although environmental modulation is superficially an attractive option, the evidence that it significantly contributes to asthma control is limited. ${ }^{2}$ House dust mite reduction is unlikely to upset to children, and allergen impermeable mattress and pillow covers may be recommended if the skin prick test to house dust mite is positive. ${ }^{2}$ In contrast, the removal of a pet from an asthmatic child with skin prick test reactivity is more problematic. If skin prick reactivity to animal dander is present, and asthma control can be achieved with moderate level of therapy, it may be less traumatic to recommend that pets should be kept out of the child's bedroom and off upholstered furniture. All parents who smoke should be regularly told that passive smoke exposure exacerbates asthma, and provided with cessation advice, or at least smoke outside the home.

\section{Drug therapy}

Drug therapy is the mainstay of asthma management. Unbiased information sources on asthma therapies include the Cochrane Airways Group reviews, the Drug and Therapeutic Bulletin (published by the Consumers' Association), and the British Guideline on the Management of Asthma. ${ }^{2}$ Treatment of asthma in adults is extensively reviewed in a recent Postgraduate Medical Journal article by Green et al. ${ }^{18}$ Indeed there is overlap between asthma management in the adults and children. For example, the recent British Thoracic Society guideline $^{2}$ considers the management of children over 12 years of age to be similar to adults. In this guideline, management is divided into five "steps". These map approximately onto the symptoms categories described by Green et al for adults, ${ }^{18}$ that is, "mild intermittent", "mild persistent", "moderate persistent", and "severe persistent". Differences in the therapeutic approach do exist between adults and children because of the lack of data from young children, concerns about the effects of corticosteroids on growth, and the overrepresentation of the "non-classical" asthma phenotypes in young children which prevents extrapolating data from trials in adults.

\section{Step 1}

For children of all ages with mild infrequent symptoms (step 1), "as required" (that is, only when symptomatic) short acting $\beta_{2}$-adrenoceptor agonist bronchodilators (salbutamol or terbutaline) are recommended. There is no additional benefit of regular short acting $\beta_{2}$-agonists during asymptomatic periods. ${ }^{19}$ Although bronchodilators are recommended for children up to 2 years of age, ${ }^{2}$ a Cochrane review concluded that there is no clear benefit of using short term $\beta_{2}$-agonists in the management of recurrent wheeze in the first two years of life. ${ }^{20}$ One problem with this review (and systematic reviews in general) is that there responsive subgroups may be overlooked. Thus, if a young child has active wheeze, it is very useful to document the clinical response to an adequate dose (4-6 puffs) of short term $\beta_{2}$-agonist. This clinical test undoubtedly detects some very young children with significant bronchodilator responsiveness.

\section{Step 2}

The next step is the introduction of inhaled corticosteroids, and is indicated if the requirement for a short acting $\beta_{2^{-}}$ agonist is more than once a day. ${ }^{2}$ Some children with less frequent usage may also benefit from this upwards step. Inhaled corticosteroids have no intrinsic bronchodilating properties, but reduce airway responsiveness, improve lung function, and reduce day-to-day symptoms. ${ }^{21}$ Three steroid preparations are currently licensed for paediatric use in the UK: beclometasone dipropionate (BDP), budesonide, and fluticasone propionate. BDP via pressurised metered dose inhaler (pMDI) is the reference compound (that is, guideline doses are expressed as BDP equivalents). Mass for mass, BDP and budesonide are approximately equivalent for clinical benefit, whereas half the mass of fluticasone is required for similar beneficial activity. ${ }^{2}$ The starting dose for children over 12 years of is $200 \mu \mathrm{g}$ equivalent of BDP twice a day, and for $100 \mu \mathrm{g}$ equivalent of BDP twice a day for both 5-12 year olds, and those under 5 years. ${ }^{2}$ All inhaled corticosteroids have the potential to cause systemic side effects, but unwanted effects can be reduced if the swallowed drug is not absorbed into the systemic circulation. Systemic bioavailability from the gut varies with corticosteroid preparation: $<1 \%$ for fluticasone propionate, $20 \%-30 \%$ for $\mathrm{BDP}$, and $11 \%$ for budesonide. ${ }^{22}$ However, when the correct delivery device is combined with the correct technique, adverse effects on adrenal function and growth are rare for all preparations. Since there is little difference in the risk/benefit ratio between BDP, budesonide, and fluticasone propionate when used correctly, the Drugs and Therapeutics Bulletin concluded in 1999 that a daily maintenance dose of up to $200 \mu \mathrm{g}$ BDP twice a day "seems a good choice".22

The British Thoracic Society guideline does not give clear advice on whether inhaled corticosteroids are indicated for preschool child with frequent episodes of viral triggered wheezing, although a systematic review by McKean and Ducharme found no evidence that regular low dose inhaled corticosteroids were effective for this phenotype. ${ }^{23}$ Indeed, inhaled corticosteroids are ineffective in the treatment of post-RSV wheeze. ${ }^{24}$ Since the possibility of a responsive preschool subgroup has not yet been excluded (that is, the minority with atopic asthma), low dose inhaled corticosteroids continue to be recommended for persistent wheeze in young children.

\section{Entering step 3}

If asthma control is inadequate, the next option is to either increase inhaled steroid, or to add a long acting $\beta$ adrenoceptor agonist (LABA). Salmeterol and formoterol are LABAs with a duration of action of at least 12 hours. The current consensus is that the risk/benefit ratio is in favour of adding in a LABA before increasing the steroid dose. ${ }^{2}$ LABAs are not licensed for children under 6 years, although there is some pilot data suggesting that they are effective. ${ }^{25}$ Children receiving a LABA with inhaled corticosteroids should continue with a "as required" short acting $\beta_{2}$-agonist. Formoterol has a more rapid onset than salmeterol, and can also be used in place of a short acting $\beta_{2}$-agonist before exercise. This option is not generally appreciated, but care must be taken that the inhaled corticosteroids are continued.

If a LABA has no effect within 2-3 weeks, it should be stopped and the inhaled steroid (BDP) dose increased to $400 \mu \mathrm{g}$ twice a day for children $>12$ years, or $200 \mu \mathrm{g}$ twice a day for 5-12 year olds. A more common scenario is that the LABA has some effect, but additional control is still required. In this case, the LABA should be continued and the steroid dose increased (to the above levels). In reality, adding in a LABA and increasing the steroid dose is frequently done at the same time. LABAs and corticosteroids are now available 
in fixed combinations; fluticasone propionate and serevent (as Seretide), and formoterol and budesonide (as Symbicort). These are slightly more convenient for parents and children, and are cheaper to the NHS. Children should be transferred onto a combination when the steroid and LABA dose has been established separately.

It is not surprising that preschool children with suboptimal control on low dose inhaled corticosteroids present a clinical problem (that is, step 2 and beyond), since LABAs are not licensed for this age group. Furthermore, the maximum dose of corticosteroids that can be prescribed before specialist respiratory referral should be considered is only $200 \mu \mathrm{g}$ twice a day (BDP or equivalent). The only option for "add on" therapy in the $2-5$ year old group is a leukotriene receptor antagonist (see below).

\section{Other options within step 3}

Before moving onto the highest inhaled steroid doses that it is reasonable to give (that is, step 4), there is the option of trying "add on" therapies. These do not replace the combination of LABA and inhaled steroid, unless the LABA is ineffective. Montelukast (Singulair) blocks the action of the potent bronchoconstricting cysteinyl leukotrienes, and is the only leukotriene receptor blocker that is licensed across the paediatric age range. Montelukast is given orally and is active for up to 24 hours. A Cochrane review which examined the efficacy of all antileukotriene agents as "add on" therapy concluded that, "although this class may slightly improve control, there is insufficient evidence to firmly support the use of licensed doses of LTRAs as add on therapy for inhaled corticosteroids" ${ }^{26}$ However, montelukast has few major side effects apart from headache and abdominal pain (although the British National Formulary cautions on the Churg-Strauss syndrome ${ }^{27}$ ), and it is reasonable to assess a four week course in all children in whom the combination of a LABA and corticosteroid has not achieved adequate symptom control. If no beneficial effect is apparent after this period, montelukast should be stopped. As discussed previously, montelukast is the only "add on" option at step 3 in children in the 2-5 year age range. ${ }^{2}$

In the past theophylline was used for paediatric asthma, but has now fallen out of favour because of its dangerous side effects in overdose. To date, there is no systematic review for its use as an add on therapy in children over 5 years where LABA have failed to improve symptoms (the guideline indication). However, a direct comparison between LABAs and oral theophylline concluded that LABAs were more effective, and were associated with fewer side effects. ${ }^{28}$ Slow release oral theophylline therefore tends to be reserved for "difficult" asthma.

\section{Steps 4 and 5}

Step 4 is the introduction of high dose inhaled corticosteroids ( $1000 \mu \mathrm{g}$ BDP equivalent twice a day for $>12$ years, and $400 \mu \mathrm{g}$ BDP equivalent twice a day for 5-12 years). Gut absorption of corticosteroids becomes more significant at higher steroid doses, and substituting BDP with budesonide or fluticasone propionate is justifiable at this stage. For preschool children, step 4 is referral to a respiratory paediatrician. Step 5 in all children above 5 years of age, is the addition of daily or alternate day oral corticosteroids in the lowest dose to provide adequate control. There is no "step 5" for preschool children in the British Thoracic Society guideline. In general, great care should be exercised when exceeding licensed doses of inhaled corticosteroids.

\section{Stepping down}

Regular follow up is essential after starting long term medication with the frequency of visits depending on symptom severity. If asthma has been well controlled for three months, the stepping up strategy should be reversed. After each downwards step, parents and children should be warned to be on the look out for subtle increases in symptoms. An increase in short term $\beta_{2}$-agonist usage is a more obvious sign that therapy reduction has failed. Stopping inhaled corticosteroids would seem a difficult decision. However, it is not uncommon to find that parents/children have decided on their own to stop corticosteroids after long asymptomatic periods.

\section{Acute asthma}

Inhaled short acting $\beta_{2}$-agonist are the primary therapy for all "attacks" of paediatric asthma. Short acting $\beta_{2}$-agonists via pMDI can be given by parents every four hours for moderately severe acute wheeze. A short 3-5 day course of oral corticosteroids may also hasten recovery from a moderate exacerbation in children $>6$ years. A written plan should be issued for attacks, even though self management plans per se have not been "proved" to be effective in improved adherence and clinical outcome. ${ }^{29}$

The approach to the management of acute asthma in hospital is similar for all children. Nebulised salbutamol or terbutaline can be used instead of pMDI delivery for severe wheeze, and this delivery method is useful when supplemental oxygen is required. However, attacks may also be managed by short acting $\beta_{2}$-agonist via pMDI and spacer. ${ }^{30}$ If initial response to the initial inhaled short acting $\beta_{2}$-agonist is poor, ipratropium bromide (an anticholinergic agent) gives additional benefit ${ }^{31}$ and a mixture of short acting $\beta_{2}$-agonist and ipratropium bromide should be initially given every 20 minutes. Since ipratropium can cause nausea in children, four hourly use is preferred for milder attacks. Systemic corticosteroids given within one hour of presentation also reduces clinical severity, ${ }^{32}$ although there is no clear evidence for an beneficial effect in preschool children. For very severe, life threatening asthma, a bolus of intravenous salbutamol may help. This can be followed by a continuous infusion of salbutamol, under intensive care conditions. Another option for a severe attacks is intravenous aminophylline followed by continuous infusion. A recent study has shown no difference between intravenous aminophylline and a bolus of salbutamol in severe paediatric asthma. ${ }^{33}$ Either therapy, but not both, is therefore currently acceptable. ${ }^{34}$ Intravenous magnesium sulphate, as a slow infusion, can provide additional bronchodilation when given in conjunction with standard bronchodilating therapies. A systematic review of intravenous magnesium, which included two paediatric trials, concluded that it appears to be safe and beneficial in acute severe asthma. ${ }^{35}$ This therapeutic option should therefore should be reserved for children with severe attacks that respond poorly to standard therapy.

\section{Difficult asthma}

This label indicates that a child should be reviewed in a specialist clinic. ${ }^{36}$ Some difficult asthmatics are compliant, and generally well controlled, but have sudden life threatening attacks. Others are non-compliant (this includes parents not delivering therapy) despite a high level of day-to-day symptoms. A third group is barely controlled by maximum doses of oral corticosteroids, despite good compliance. Assessment has to be tailored to the individual child. The diagnosis should be questioned again: could there be a comorbidly due to bronchiectasis, gastro-oesophageal reflux, cardiac arrhythmias, anaphylaxis, or psychological issues? Additional markers of asthmatic inflammation may be helpful. These include exhaled nitric oxide and induced sputum, although they remain research tools. Future research will assess whether tailoring therapy to the underlying inflammatory phenotype rather than symptoms alone, provides better asthma control-that is, increasing inhaled 
steroids if the inflammatory markers are high, even if the child is clinically "stable"; alternatively increasing bronchodilators and not steroids if the child is symptomatic-but the inflammatory markers are low. Inhaler technique should be reassessed and details of prescriptions from the general practitioner obtained. Specialist prescribed therapies include alternate day oral corticosteroids, intramuscular triamcinolone, and subcutaneous terbutaline.

\section{Drug delivery devices}

Inhaled drugs are the mainstay of asthma treatment. The pMDI and spacer combination remains the gold standard delivery device for children. A mask should be added to the spacer in young children. ${ }^{37}$ More portable devices include the breath actuated MDI and dry powder inhalers. There are no major difference in drug delivery when these different systems are used correctly. ${ }^{2}$ Most children and parents remain happy with the pMDI and spacer for twice a day use, but a portable device for "as required" inhalation is often appreciated. Nebulised therapy is reserved for severe acute asthma, and the occasional child who has a tantrum whenever the spacer is placed near its face (budesonide is available as a nebulised solution). Since the clinical effect of short acting $\beta_{2}$-agonists in stable paediatric asthma is independent of the delivery device, ${ }^{38}$ personal preference therefore dictates whether terbutaline (available as a pMDI and dry powder breath actuated device) or salbutamol (available as a pMDI, breath actuated MDI, or dry powder breath actuated device) is chosen. Salmeterol is available as a pMDI and dry powder (Accuhaler), whereas formoterol is only available as a dry powder (Turbohaler).

\section{Education}

It is important for clinicians and asthma nurses to see children with persistent asthma when they are well in order to discuss what asthma is, to demonstrate and check inhaler technique, to re-evaluate the most convenient delivery device, to make sure that the written action plan is understood, and to ensure that any emergency medication (such as a short course of oral steroids) is not out of date or lost. The value of a proactive approach has been demonstrated in children with persistent asthma who were randomised to either three scheduled visits within a two month period when the child was well, or "routine" care. ${ }^{39}$ During a one year follow up, the intervention group used less "as required" bronchodilators, and their technique was consistently better than the control group.

\section{QUESTIONS (TRUE (T)/FALSE (F); ANSWERS AT END OF REFERENCES)}

1. Regular inhaled corticosteroids:

(A) Are useful in preventing viral triggered attacks of asthma in preschool children

(B) Are used at step 1 of the British Thoracic Society guidelines

(C) Suppress inflammation in atopic asthma

(D) Should be stopped when starting a long acting $\beta_{2^{-}}$ agonist (LABA)

(E) Are unlikely to suppress growth when used at licensed doses

2. Asthma in preschool children:

(A) Is usually triggered by viral colds

(B) Persists into school age in the majority of affected children

(C) Is impossible to distinguish from bronchiolitis

(D) Can be treated with a LABA
(E) "As required" short acting $\beta_{2}$-agonists are the mainstay of therapy

3. Leukotriene antagonists for children:

(A) Have a duration of action of three hours

(B) Are the only option for "add on" therapy in a preschool child receiving inhaled steroids and a short acting $\beta_{2}$-agonist

(C) Should be tried before a LABA in school age children

(D) Are inhaled

(E) May cause headache

I have received financial support to attend conferences from Astra, 3M, Merck (UK), Glaxo-Wellcome, and payment for lectures given at educational meetings from Astra, Merck (UK), and Glaxo-Wellcome. I have also been a co-investigator on a asthma genetics study funded by Glaxo-Wellcome.

\section{REFERENCES}

1 Smyth RL. Asthma: a major pediatric health issue. Respir Res 2002;3(suppl 1):S3-7. 2 British guideline on the management of asthma. Thorax 2003;58(suppl
1):i1-94.

3 Taussig LM, Wright AL, Holberg CJ, et al. Tucson Children's Respiratory Study: 1980 to present. J Allergy Clin Immunol 2003;111:661-75.

4 Martinez FD. The natural history of asthma during childhood. In: Silverman M, ed. Childhood asthma and other wheezing disorders. London: Arnold, 2002:29-36.

5 Horak $\mathrm{E}$, Lanigan $\mathrm{A}$, Roberts $\mathrm{M}$, et al. Longitudinal study of childhood wheezy bronchitis and asthma: outcome at age 42. BMJ 2003;326:422-3.

6 Wolfe R, Carlin JB, Oswald $\mathrm{H}$, et al. Association between allergy and asthma from childhood to middle adulthood in an Australian cohort study. Am J Respir Crit Care Med 2000;162:2177-81.

7 American Academy of Allergy Asthma, Immunology, eds. Pediatric asthma. Promoting best practice. Guide for managing asthma in children. Milwaukee: American Academy of Pediatrics, 1999:1-139.

8 McNamara PS, Smyth RL. The pathogenesis of respiratory syncytial virus disease in childhood. Br Med Bull 2002;61:13-28.

9 Wennergren G, Kristjansson S. Relationship between respiratory syncytial virus bronchiolitis and future obstructive airway diseases. Eur Respir $J$ 2001;18:1044-58.

10 Turner SW, Young S, Landau LI, et al. Reduced lung function both before bronchiolitis and at 11 years. Arch Dis Child 2002;87:417-20.

11 Martinez FD, Godfrey S, eds. Epidemiology of wheezing in infants and young children. Wheezing disorders in the preschool child. London and New York: Martin Dunitz, 2003:1-19.

12 Ying S, Durham SR, Corrigan CJ, et al. Phenotype of cells expressing mRNA for TH2-type (interleukin 4 and interleukin 5) and TH1-type (interleukin 2 and interferon gamma) cytokines in bronchoalveolar lavage and bronchial biopsies from atopic asthmatic and normal control subjects. Am J Respir Cell Mol Biol 1995;12:477-87.

13 Walsh GM, Hartnell A, Wardlaw AJ, et al. IL-5 enhances the in vitro adhesion of human eosinophils, but not neutrophils, in a leucocyte integrin (CD 1 1 / 18)dependent manner. Immunology 1990;71:258-65.

14 Louis $R$, Lau $L C$, Bron $A O$, et al. The relationship between airways inflammation and asthma severity. Am J Respir Crit Care Med 2000;161:9-16.

15 Gibson PG, Simpson JL, Hankin R, et al. Relationship between induced sputum eosinophils and the clinical pattern of childhood asthma. Thorax 2003;58:116-21.

16 Stevenson EC, Turner G, Heaney LG, et al. Bronchoalveolar lavage findings suggest two different forms of childhood asthma. Clin Exp Allergy 1997;27:1027-35.

17 Sly PD, Flack FS. Lung function. In: Silverman M, ed. Childhood asthma and other wheezing disorders. London: Arnold, 2002:125-43.

18 Green RH, Brightling CE, Pavord ID, et al. Management of asthma in adults: current therapy and future directions. Postgrad Med J 2003;79:259-67.

19 Walters EH, Walters JA, Gibson PW. Regular treatment with long acting beta agonists versus daily regular treatment with short acting beta agonists in adults and children with stable asthma. Cochrane Database Syst Rev 2002:CD003901.

20 Chavasse R, Seddon P, Bara A, et al. Short acting beta agonists for recurrent wheeze in children under 2 years of age. Cochrane Database Syst Rev 2002:CD002873.

21 Adams NP, Bestall JB, Jones PW. Inhaled beclomethasone versus placebo for chronic asthma. Cochrane Database Syst Rev 2000:CD002738.

22 Anonymous. The use of inhaled corticosteroids in childhood asthma. Drug and Therapeutics Bulletin 1999;37:73-7.

23 McKean M, Ducharme F. Inhaled steroids for episodic viral wheeze of childhood. Cochrane Database Syst Rev 2000:CD001107.

24 Fox GF, Everard ML, Marsh MJ, et al. Randomised controlled trial of budesonide for the prevention of post-bronchiolitis wheezing. Arch Dis Child 1999;80:343-7. 
25 Primhak RA, Smith CM, Yong SC, et al. The bronchoprotective effect of inhaled salmeterol in preschool children: a dose-ranging study. Eur Respir J 1999;13:78-81

26 Ducharme F, Hicks G, Kakuma R. Addition of anti-leukotriene agents to inhaled corticosteroids for chronic asthma. Cochrane Database Syst Rev 2002:CD003133.

27 Joint Formulary Committee, ed. Respiratory system. British national formulary. London: British Medical Association and the Royal Pharmaceutical Society of Great Britain, 2003:130-64.

28 Wilson AJ, Gibson PG, Coughlan J. Long acting beta-agonists versus theophylline for maintenance treatment of asthma. Cochrane Database Syst Rev 2000:CD001281.

29 Toelle BG, Ram FS. Written individualised management plans for asthma in children and adults. Cochrane Database Syst Rev 2002:CD002171.

30 Benton G, Thomas RC, Nickerson BG, et al. Experience with a metered-dose inhaler with a spacer in the pediatric emergency department. Am J Dis Child $1989 ; 143: 678-81$.

31 Plotnick LH, Ducharme FM. Combined inhaled anticholinergics and beta2agonists for initial treatment of acute asthma in children. Cochrane Database Syst Rev 2000:CD000060

32 Rowe BH, Spooner C, Ducharme FM, et al. Early emergency department treatment of acute asthma with systemic corticosteroids. Cochrane Database Syst Rev 2001:CD002178.
33 Roberts G Newsom D, Gomez K et al Intravenous salbutamol bolus compared with an aminophylline infusion in children with severe asthma: a randomised controlled trial. Thorax 2003;58:306-10.

34 South $M$. Second line treatment for severe acute childhood asthma. Thorax 2003:58:284-5.

35 Rowe BH, Bretzlaff JA, Bourdon C, et al. Intravenous magnesium sulfate treatment for acute asthma in the emergency department: a systematic review of the literature. Ann Emerg Med 2000;36:181-90.

36 McKenzie SA, Bush A. Difficult asthma in children. Thorax 2002;57:915-16.

37 National Institute for Clinical Excellence. Guidance on the use of inhaler systems (devices) in children under the age of 5 years with chronic asthma. London: NICE, 2000:1-11

38 Ram FS, Brocklebank DM, White J, et al. Pressurised metered dose inhalers versus all other hand-held inhaler devices to deliver beta-2 agonist bronchodilators for non-acute asthma. Cochrane Database Syst Rev 2002:CD002158

39 Glasgow NJ, Ponsonby AL, Yates R, et al. Proactive asthma care in childhood: general practice based randomised controlled trial. BMJ 2003;327:659.

\section{ANSWERS}

1. (A) F, (B) F, (C) T, (D) F, (E) T; 2. (A) T, (B) F, (C) F, (D) F, (E) $\mathrm{T}$; 3. (D) (A) F, (B) T, (C) F, (D) F, (E) T.

\section{Making Health Care Safer 2004}

21-22 October 2004

Royal College of Physicians, London

A two day conference for all professionals dedicated to providing safer health care for all.

Register now! Early booking discount available.

See website for details: www.quality.bmipg.com 